\title{
Misinformed About the Affordable Care Act? Leveraging Certainty to Assess the Prevalence of Misperceptions
}

\author{
Josh Pasek ${ }^{1}$, Gaurav Sood ${ }^{2}$, \& Jon A. Krosnick ${ }^{3}$ \\ 1 Department of Communication Studies, University of Michigan, Ann Arbor, Ml 48103, USA \\ 2 McCourt School of Public Policy, Georgetown University, Washington, DC 20015, USA \\ 3 Departments of Communication, Political Science, and Psychology, Stanford University, Stanford, CA 94305 , \\ USA
}

\begin{abstract}
According to some recent research, Americans hold a great deal of misinformation about important political issues. However, such investigations treat incorrect answers to quiz questions measuring knowledge as evidence of misinformation. This study instead defines misperceptions as incorrect answers that respondents are confident are correct. Two surveys of representative samples of American adults on the Affordable Care Act reveal that most people were uncertain about the provisions in the law. Confidently held incorrect beliefs were far less common than incorrect answers. Misperceptions were most prevalent on aspects of the law on which elites prominently and persistently made incorrect claims. Furthermore, although Americans appear to have learned about the law between 2010 and 2012, misperceptions on many provisions of the law persisted.
\end{abstract}

Keywords: Misinformation, Certainty, Political Knowledge, Affordable Care Act.

doi:10.1111/jcom.12165

Much research suggests that the information that people have about political issues affects their policy preferences and behaviors (Bartels, 1996; Gilens, 2001; Luskin, Fishkin, \& Jowell, 2002). Until recently, however, work studying how informed people are about issues has focused on the possession of correct beliefs and ignored possession of incorrect beliefs (Kuklinski, Quirk, Jerit, Schwieder, \& Rich, 2000).

In this study, we suggest that researchers should distinguish between ignorance (defined as lacking a correct belief on an issue) and misperception (defined as holding an incorrect belief with confidence). Whereas ignorance is lamentable in a democratic society, misperceptions have the potential to be dangerous. We demonstrate one

Corresponding author: Josh Pasek; e-mail: jpasek@umich.edu 
approach to empirically distinguish between these two forms of lack of correct information and discuss what doing so says about the American public's understanding of the Patient Protection and Affordable Care Act (ACA).

\section{Challenges in measuring misperceptions}

Studies of the prevalence, predictors, and consequences of incorrect beliefs have often used knowledge quizzes to measure this construct (Hofstetter, Barker, Smith, Zari, \& Ingrassia, 1999; Jerit \& Barabas, 2006; Kull, Ramsay, \& Lewis, 2003). However, incorrect answers can stem from incorrect beliefs, off-target inferences, or guessing, and traditional knowledge quizzes do not afford a way to distinguish between these alternatives. Thus, the proportion of incorrect answers to quiz questions is not a measure of misinformation. ${ }^{1}$

Much past research on misinformation has focused on widely disseminated incorrect claims (Hofstetter et al., 1999; Meirick, 2013), such as that Saddam Hussein was connected to Osama bin Laden (Prasad et al., 2009) and the assertion that President Obama was not born in the United States (Crawford \& Bhatia, 2012; Krosnick, Malhotra, \& Mittal, 2014; Pasek, Stark, Krosnick, \& Tompson, 2014). In the domain of the ACA, the contention that the law would create "death panels" (Meirick, 2013; Nyhan, 2010) has been the subject of much research. However, focusing on widespread rumors means that researchers have rarely studied instances in which incorrect claims were less widely disseminated through popular media. And we do not know if inaccurate beliefs are any less common on those kinds of topics.

To measure misperceptions, we need to distinguish incorrect answers to quiz questions that are held with confidence from incorrect answers people aren't sure about. To do so, we conducted two surveys in which factual quiz questions were followed by questions asking how certain the respondent was of each answer. In line with Kuklinski and colleagues, we treat incorrect beliefs held with certainty as misperceptions (Kuklinski \& Quirk, 2001; Kuklinski et al., 2000). Incorrect answers offered with low certainty are treated as indicators of ignorance.

\section{The current study}

We used data from two surveys on the ACA to assess the scope and nature of the incorrect beliefs that Americans held about the law. We combined certainty assessments with incorrect answers to quiz questions to build a measure of misperceptions for each of various attributes of the law in each of the two surveys. We used these measures to describe the scope of misperceptions.

\section{Methods}

\section{Data}

Two surveys of nationally representative samples of American adults were conducted by GfK Custom Research. A total of 1,251 individuals were interviewed between 31 August and 7 September 2010, and another 1,334 individuals were 
interviewed between 3 August and 13 August 2012. Respondents were drawn from the KnowledgePanel ${ }^{\circledR}$, a group of individuals selected via probability sampling (via random-digit dialing and address-based sampling using the USPS Computerized Delivery Sequence File) who agreed to complete online surveys regularly. Respondents who did not have a computer or Internet access were provided those at no cost. The response rates for the 2010 and 2012 surveys (cumulative with panel recruitment, CUMMRR3) were 12.0 and 9.9\%, respectively (see Callegaro \& Disogra, 2008). Weights were constructed to match demographics from the most recent Current Population Survey data available at the time of survey administration, and all analyses were conducted with weights.

\section{Information and certainty measures \\ Quiz questions}

Respondents reported whether 18 provisions were included in the ACA. A “Don't Know" option was not offered (cf. Mondak, 2001; Mondak \& Davis, 2001). ${ }^{2}$ Twelve of the items were about requirements or provisions in the ACA; the rest were about provisions that were not in the legislation (see Table 1). Items in the law were chosen from a comprehensive summary of the law's principal provisions. The other six items addressed false claims that had been made frequently in news coverage of the ACA. Instructions for responding to these questions are provided in the Appendix S1, Supporting Information; measures and distributions of responses to each item are shown in Table 1 and Figure $1 .^{3}$ Across both surveys, no more than $3.8 \%$ of respondents skipped any question, and $87.8 \%$ of respondents answered all 18 questions. Individuals who failed to answer a question were treated as having answered neither correctly nor incorrectly on that question.

Knowledge of the provisions varied widely - for some provisions, the vast majority of respondents offered the correct answer (e.g., that individuals under age 26 can stay on their parents' insurance and that large companies were required to provide insurance for their employees). For other provisions, individuals performed no better than chance (e.g., fees for drug makers and subsidies for low income individuals; see Table 1). The provisions varied widely in the amount of information that was disseminated about them; incorrect claims were made frequently in public discourse about some plan attributes (e.g., death panels), and little was said about other plan attributes (e.g., a soda tax or fees for insurance companies).

\section{Certainty}

After each knowledge question, respondents were asked, "How sure are you about this?" - "Extremely sure," "Very sure," "Moderately sure," "Slightly sure," or "Not sure at all." Answers were coded as follows: "Not sure at all" $=0$, "Slightly sure" $=.25$, "Moderately sure" $=.5$, "Very sure" $=.75$, and "Extremely sure" $=1$.

\section{Misperceptions}

Respondents were regarded as holding misperceptions if they were very sure or extremely sure about an incorrect answer (coded 1, and coded 0 otherwise). 


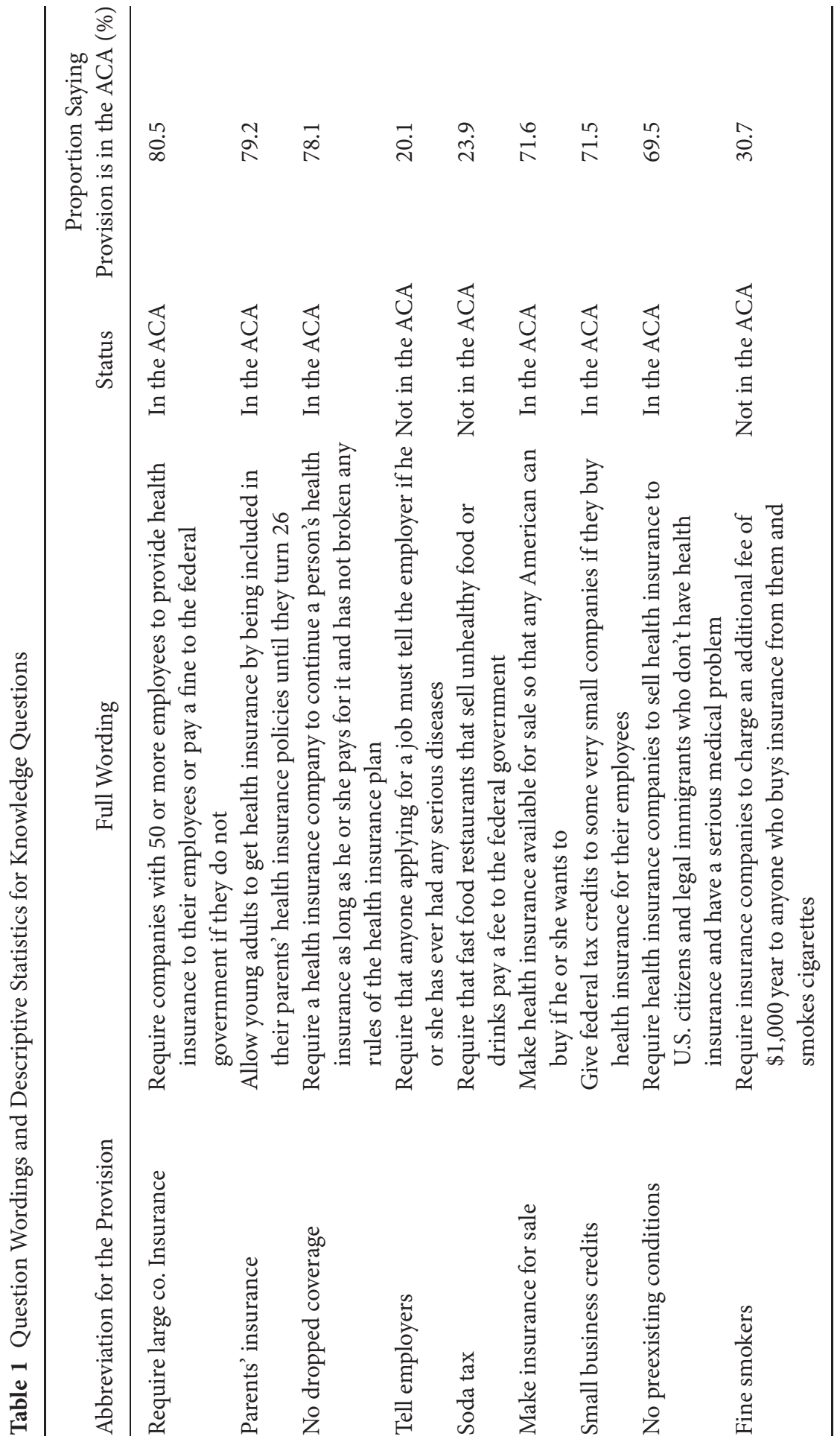




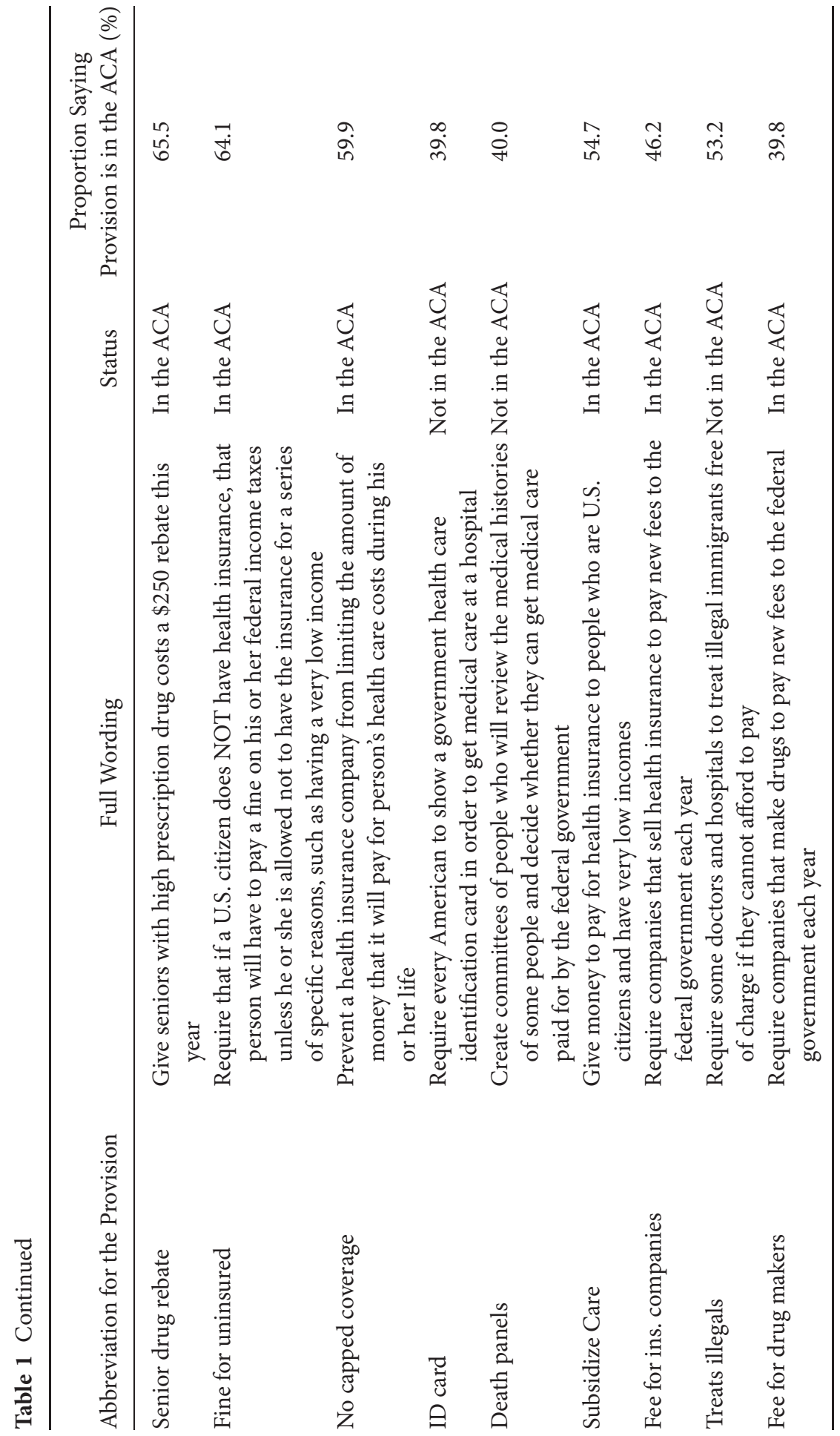




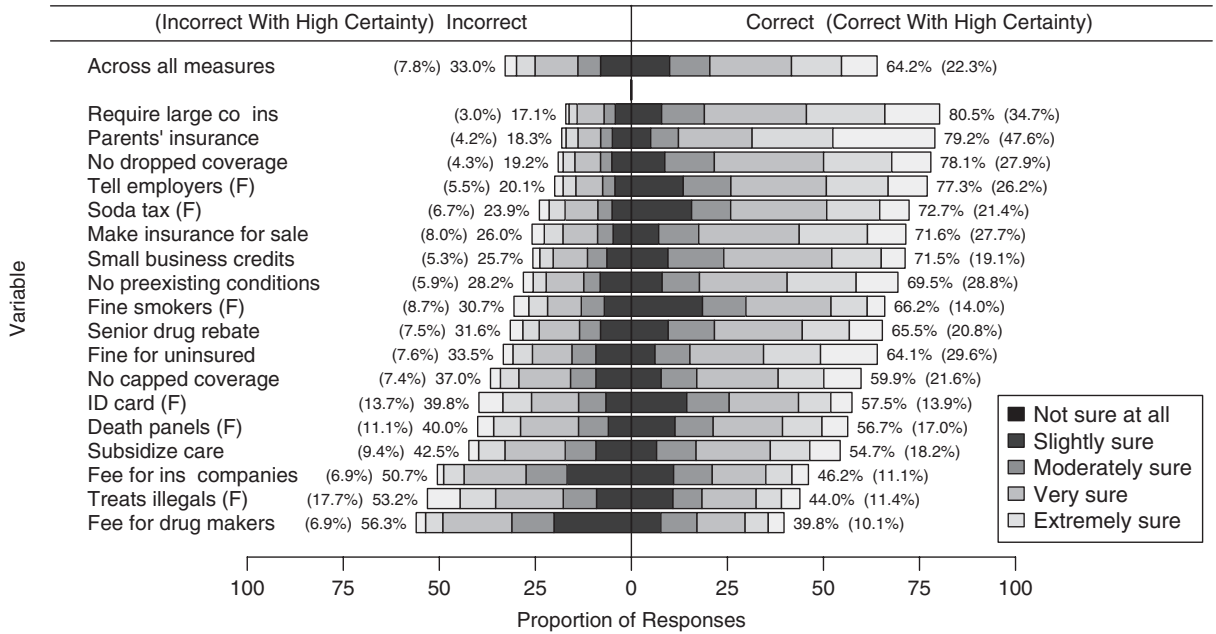

Figure 1 Distributions of all certainty-correctness combinations across both years. Missing data are included in calculating the percentages, but the percentages of missing data are not shown. (F) Denotes items for which the correct answer was that the provision was not in the law.

\section{Results}

\section{Frequencies of correct and incorrect answers}

All provisions

Across the two surveys, respondents answered $64.2 \%$ of the items correctly, $33.0 \%$ incorrectly, and skipped $2.8 \%$ of the items (see Figure 1). Across the 18 items, on average, respondents answered 11.6 items correctly and answered 5.9 incorrectly. Vanishingly few respondents answered all the questions correctly (.05\%), and no respondents answered all questions incorrectly. Only $1.2 \%$ of respondents declined to answer all questions.

Between 2010 and 2012, the proportion of questions that respondents declined to answer increased from $1.2 \%$ to $4.4 \%(\Delta=3.2, \mathrm{t}=6.3, \mathrm{p}<.001)$; this led respondents to appear both less knowledgeable and less misinformed over time (see Table 2). In 2010, respondents answered $65.0 \%$ of the questions correctly. In 2012, only $63.4 \%$ did, a small but significant decline of 1.6 percentage points $(\mathrm{t}=-2.3, \mathrm{p}=.02)$. The frequency of incorrect answers declined from $33.8 \%$ in 2010 to $32.2 \%$ in 2012 $(\Delta=-1.6, \mathrm{t}=-2.7, \mathrm{p}=.007)$. Among the substantive answers offered, the proportion correct did not differ across years $(65.7 \%$ vs. $66.2 \%$ of answers were correct in 2010 and 2012, respectively, $\mathrm{t}=.93, \mathrm{p}=.35)$.

\section{Individual provisions}

According to the traditional measures, awareness of the elements of the law varied considerably across provisions. Nearly $80 \%$ of respondents accurately reported that large companies would be required to provide insurance for their employees, that 


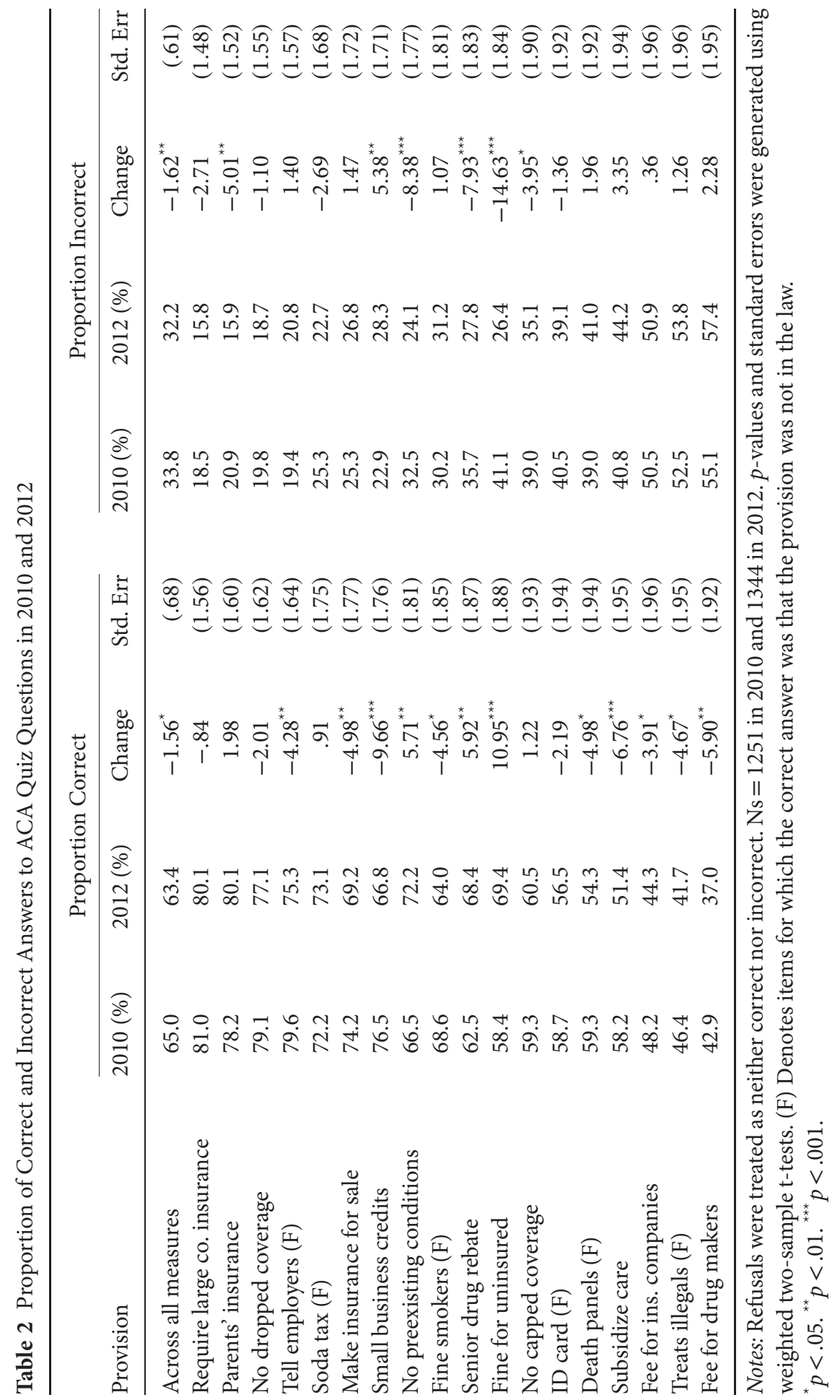


young adults could remain on their parents' plans, and that insurance companies could no longer drop coverage (Figure 1). However, a majority of respondents incorrectly reported that the law would not introduce a fee for drug makers (56.3\%), that it would require the treatment of illegal immigrants (53.2\%), and that insurance companies would not be charged a fee $(50.7 \%)$. Thus, according to the traditional measure, inaccurate beliefs about some of the less-discussed elements of the plan were common.

Using the proportion correct and incorrect measures, Americans' awareness of many aspects of the law fluctuated between 2010 and 2012. The percentage of Americans correctly reporting that the law would impose a fine on uninsured individuals rose by 11.0 percentage points between 2010 and $2012(t=5.8, p<.001$; Table 2). Americans also became more likely to correctly report that the law prevented discrimination based on preexisting conditions $(\Delta=5.7, \mathrm{t}=3.2, \mathrm{p}=.002)$ and that it would provide seniors with a drug rebate $(\Delta=5.9, \mathrm{t}=3.2, \mathrm{p}=.002)$. In contrast, in 2012, Americans were far less aware of small business tax credits $(\Delta=-9.7, \mathrm{t}=-5.5$, $\mathrm{p}<.001)$, subsidies for low income Americans $(\Delta=-6.8, \mathrm{t}=-3.5, \mathrm{p}<.001)$, and fees for drug manufacturers $(\Delta=-5.9, \mathrm{t}=-3.1, \mathrm{p}=.002)$. Compared to 2010, respondents in 2012 were also less likely to offer incorrect answers on questions about five of the provisions: fines for the uninsured, preexisting conditions, the ability to stay on parental insurance until age 26 , and the end of coverage caps $(\Delta s<-3.9$, ts $>2.0$, ps $<.04)$. The only significant increase in incorrect answers was on small businesses tax credits $(\Delta=5.4, \mathrm{t}=3.1, \mathrm{p}=.002)$.

\section{Frequency of high-confidence answers}

In general, respondents were only moderately certain about their answers. Respondents reported that they were "not at all sure" about 19.1\% of their answers, "slightly sure" about $16.4 \%$, "moderately sure" about $32.5 \%$, "very sure" about $17.9 \%$, and "extremely sure" about $12.2 \%$ of their answers. Respondents chose not to answer the certainty question for $1.8 \%$ of the provisions.

When respondents answered the quiz questions correctly, they were more certain than when they answered incorrectly. Respondents were "very sure" or "extremely sure" for $34.8 \%$ of correct answers and for $22.9 \%$ of incorrect answers $(p<.001)$. In all, respondents answered $22.3 \%$ of all questions correctly with high certainty and answered $7.8 \%$ of the questions incorrectly with high certainty (see Figure 1). Although confidently held accurate beliefs were more common than confidently held inaccurate beliefs, misperceptions were common.

\section{Certainty-adjusted measures}

All provisions

In contrast to the traditional measures, certainty-adjusted measures suggest that Americans became better informed about the provisions in the ACA. Highly certain correct answers became more common between 2010 and 2012, rising from 21.2 to $23.3 \%(\Delta=2.2, \mathrm{t}=2.5, p=.01)$, while the percentage of highly certain incorrect answers remained largely unchanged at 8.1 and $7.4 \%$ respectively $(\Delta=-.7, \mathrm{t}=-1.4$, $p=.16$; Table 3 ). 


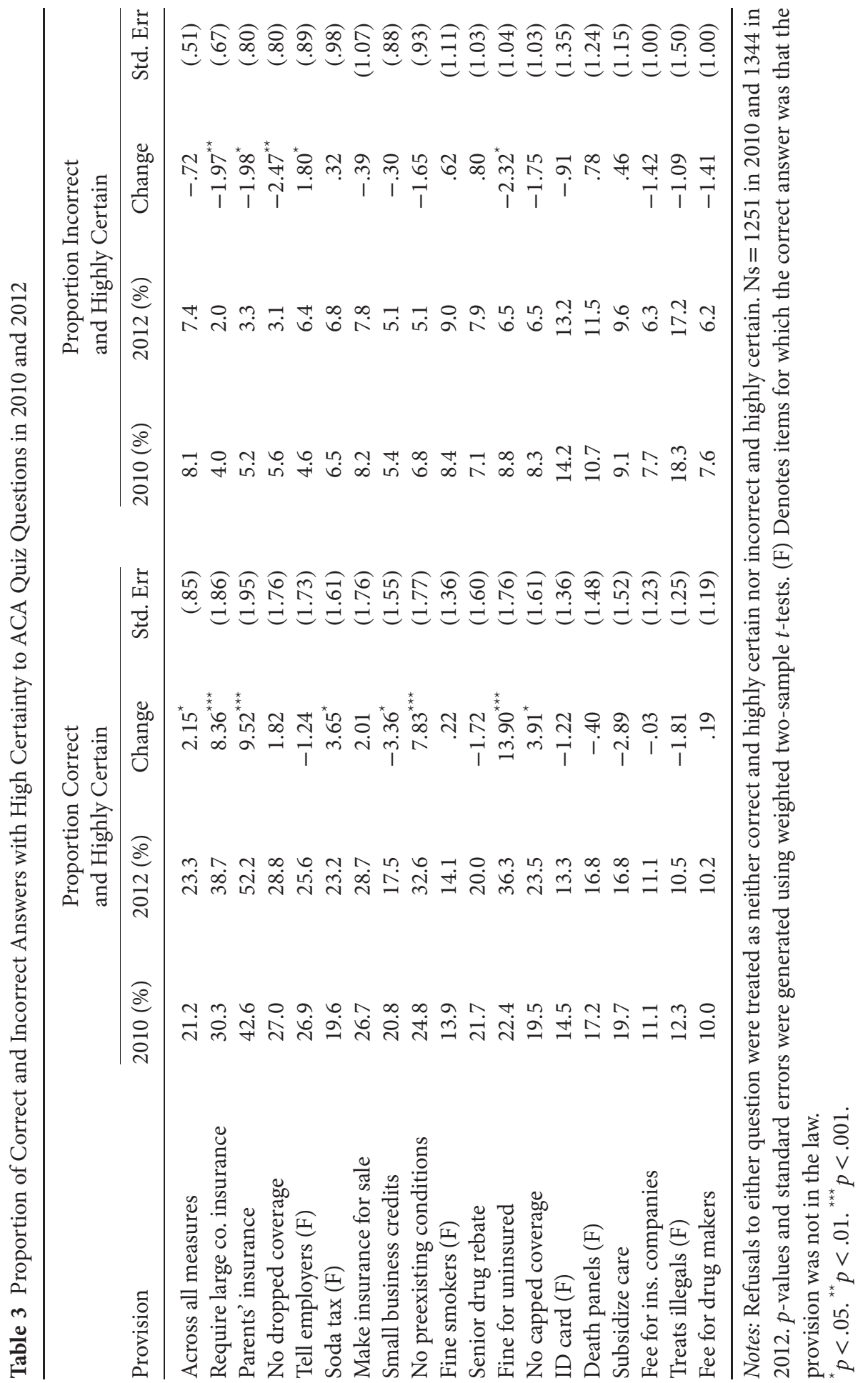




\section{Individual provisions}

The proportions of high-confidence correct responses and high-confidence incorrect responses varied considerably across provisions. Respondents were most knowledgeable about the provision that young adults could remain on their parents' insurance (47.6\% answered correctly with high certainty, see Figure 1). Respondents were least knowledgeable about fees for drug manufacturers; only $10.1 \%$ answered this question correctly with high certainty. The percentage misperceiving a provision ranged from a low of $3.1 \%$, about whether large companies would be required to provide insurance for their employees, to $17.9 \%$, about whether the law mandated treatment of illegal immigrants.

Furthermore, compared to a by-definition perfect negative correlation between the prevalence of correct and incorrect answers ignoring certainty $(r=-1.00)$, the correlation between the prevalence of highly certain correct answers and highly certain incorrect responses was much weaker $(r=-.61)$. Thus, the provisions about which people knew the most were not necessarily the provisions about which misperceptions were the least common.

Between 2010 and 2012, using certainty-weighted answers, respondents' understanding about some of the provisions of the law improved. Compared to 2010, respondents in 2012 were much more likely to know about fines on the uninsured $(\Delta=13.9, \mathrm{t}=7.9, p<.001$, Table 3$)$, allowing young adults to stay on their parents' plans $(\Delta=9.5, \mathrm{t}=4.9, p<.001)$, requiring large employers to offer insurance $(\Delta=8.4$, $\mathrm{t}=4.5, p<.001)$, and outlawing denial based on preexisting conditions $(\Delta=7.8$, $\mathrm{t}=4.4, p<.001$ ). Respondents in 2012 were also significantly more likely to know that coverage could no longer be capped $(\Delta=3.9, \mathrm{t}=2.4, p=.02)$ and that a soda tax was not part of the plan $(\Delta=3.6, \mathrm{t}=2.3, p=.02)$. Small business tax credits was the only provision about which knowledge significantly declined over time $(\Delta=-3.4$, $\mathrm{t}=-2.2, p=.03$ ). These results imply that Americans were learning about the ACA, even though the total number of correct answers did not increase appreciably during this period.

Whereas knowledge gains were principally associated with declines in the prevalence of low-certainly beliefs, knowledge gains were also sometimes accompanied by a reduction in the frequency of misperceptions. Respondents were less likely to provide confident incorrect answers about requirements for large companies to provide insurance $(\Delta=-2.0, \mathrm{t}=-2.9, p=.003$, Table 3$)$, coverage of young adults on their parents' plans $(\Delta=-2.0, \mathrm{t}=-2.5, p=.01)$, limits on dropped coverage $(\Delta=-2.5, \mathrm{t}=-3.1$, $p=.002)$, and fines for uninsured individuals $(\Delta=-2.3, \mathrm{t}=-2.2, p=.03)$. The only item on which misperceptions increased significantly between 2010 to 2012 was on the requirement to disclose medical conditions to employers $(\Delta=1.8, \mathrm{t}=2.0, p=.02)$.

\section{Discussion}

Traditional measures of knowledge accuracy suggest that many Americans were misinformed about the law's contents. Indeed, a large percentage of people incorrectly answered at least some questions about the provisions in the law. However, many 
Americans were unsure about the incorrect answers they gave, suggesting that they were often more uninformed than misinformed about the law.

Much past research on misinformation has assumed that anyone who answered quiz questions incorrectly was misinformed. Instead, however, many of our survey respondents were unsure about the incorrect answers they gave, perhaps because they had merely guessed incorrectly. By allowing individuals to tell us when they were confident about the veracity of their answers, we could distinguish between ignorance and misperception.

Distinguishing between misperceptions and unconfidently held incorrect beliefs yielded a different story about the prevalence of misinformation about the ACA, as well as how this phenomenon changed over time. Although a majority of respondents answered questions about fees for drug makers and insurance companies incorrectly, few respondents were confident about their incorrect answers, suggesting that ignorance was prevalent. It is perhaps unsurprising that these provisions were relatively unknown; they were not a major component of the administration's advocacy efforts (U.S. Department of Health and Human Services, 2013), criticism of the law (ObamaCare Facts, n.d.), or widespread rumoring (Holan, 2013). ${ }^{4}$ In contrast, "death panels," a healthcare ID card, and required treatments for illegal immigrants were answered inaccurately with confidence quite often, in line with their status as topics of widespread rumoring (Holan, 2013; TruthorFiction.com, 2015). Notably, the prevalence of misperceptions about these provisions remained largely static from 2010 to 2012.

In contrast to the proportion correct measure, which indicated that people learned about some provisions and became less informed about others, the confidence-adjusted measures documented increases in knowledge of some of the most widely discussed provisions of the ACA. Awareness of employer mandates, parental insurance coverage, fines for the uninsured, and the end of preexisting conditions increased from 2010 to 2012 (cf. ObamaCare Facts, n.d.). These were many of the same provisions for which the prevalence of misperceptions decreased over time. Hence, the confidence-adjusted measures suggest that discussion of the plan between 2010 and 2012 increased awareness of the law's key provisions.

\section{Limitations and future studies}

There are limitations inherent in using certainty measures to distinguish misperceptions from ignorance. First, picking a particular threshold for the level of certainty that distinguishes ignorance from misperception is subjective. Some researchers have suggested that answers to factual questions reflect 'expressive responding' (Bullock, Gerber, Hill, \& Huber, 2013; Prior, Sood, \& Khanna, 2013). ${ }^{5}$ For instance, Republicans who disliked Democrats may have said that they were certain that a disliked provision was in the ACA, despite not knowing whether the provision was in the bill, simply because they disliked it. People might also have reported higher certainty for answers that confirmed their preexisting attitudes. As expressive responding would present challenges for all knowledge measurement, future studies 
should assess whether certainty-adjusted measures are more or less sensitive to these processes. And finally, individuals who hold identical beliefs with identical levels of certainty may nonetheless answer certainty questions differently either because of overconfidence (Ortoleva \& Snowberg, 2013) or because they interpret the meanings of the rating scale points differently. Therefore, differences in knowledge and misinformation we observed may be due to shifts in the accuracy of beliefs among individuals who expressed consistently high (or low) certainty. All of these concerns suggest that confidently held answers are not a perfect metric for the substantive beliefs that people hold and use, though using certainty is likely a better indicator than a simple tally of correct or incorrect responses.

\section{Conclusion}

This study indicates that the practice of distinguishing between individuals who are certain about incorrect beliefs (i.e., hold misperceptions) and those who are incorrect and unsure can alter the substantive conclusions that researchers reach. Incorrect answers to questions about the Affordable Care Act were far more common than confidently held incorrect responses. Furthermore, confidently held misperceptions were most common for provisions about which inaccurate rumors spread most prominently. Moreover, where accurate information was widely disseminated, respondents increasingly held correct beliefs with confidence. These increases were associated with a corresponding reduction in both less confidently held beliefs and some reduction in confidently held incorrect beliefs. Similar changes were not observed, however, for less widely discussed provisions of the law. Thus, despite widespread inaccuracy in responses to quiz questions about the ACA, our results provide hopeful evidence that most Americans were not mired in a web of misinformation and that dissemination of correct information about the law can alter beliefs.

\section{Acknowledgments}

The authors thank Arthur Lupia, Nick Allum, Stuart Soroka, and Carl Palmer for their advice and Trevor Tompson for arranging for the data collection. Data collection was funded by the Robert Wood Johnson Foundation, and the research project was conducted by Stanford University, GfK Custom Research, and the Associated Press. Jon Krosnick is University Fellow at Resources for the Future.

\section{Notes}

1 One can try to adjust for guessing-related error by assuming that guessing is random. For example, if a quiz question offers two possible answers, then one might assume that respondents who guess the answer have a $50 \%$ chance of answering incorrectly. But such adjustments can only be made in the aggregate and do not deliver individual level measures that we would ideally like to have. Moreover, much past research shows that guessing is often biased (Attali \& Bar-Hillel, 2003). Even when asked to select randomly between offered options, respondents' selections show asymmetic patterns (Ayton, Hunt, \& Wright, 1989). 
2 See Luskin and Bullock (2011) for a contrary position.

3 A 19th question was asked in 2010, but was not included in the analyses reported here, because the question wording made it ambiguous as to whether the provision was in the bill.

4 Because many of the provisions of the law were not associated with consistent terminology and the words used were common to news coverage of the law (e.g., "drug" and "fee" appeared many times in news articles although it was not a widely discussed provision), there was no way to identify the prevalence of discussion about these provisions in a search of news articles. Instead, we considered whether information about the law or formal responses to rumors about the law mentioned these provisions as a way of indexing their commonality. For comparison purposes, a Lexis-Nexis search of the prevalence of related terms is shown in Table A1 in Online Appendix S1.

5 Berinsky (2015) found that expressive responding was relatively rare.

\section{References}

Attali, Y., \& Bar-Hillel, M. (2003). Guess where: The position of correct answers in multiple-choice test items as a psychometric variable. Journal of Educational Measurement, 40(2), 109-128. doi:10.1111/j.1745-3984.2003.tb01099.x.

Ayton, P., Hunt, A. J., \& Wright, G. (1989). Psychological conceptions of randomness. Journal of Behavioral Decision Making, 2(4), 221 -238. doi:10.1002/bdm.3960020403.

Bartels, L. M. (1996). Uninformed votes: Information effects in presidential elections. American Journal of Political Science, 40(1), 194-230. doi:10.2307/2111700.

Berinsky, A. (2015). Telling the truth about believing the lies? Paper presented at the Conspiracy Theories Conference, Coral Gables, FL.

Bullock, J., Gerber, A. S., Hill, S., \& Huber, G. (2013). Partisan bias in factual beliefs about politics. Working Paper No. 19080, National Bureau of Economic Research, Cambridge, MA. Retrieved from nber.org.

Callegaro, M., \& Disogra, C. (2008). Computing response metrics for online panels. Public Opinion Quarterly, 72(5), 1008 - 1032. doi:10.1093/poq/nfn065.

Crawford, J. T., \& Bhatia, A. (2012). Birther nation: Political conservatism is associated with explicit and implicit beliefs that President Barack Obama is foreign. Analyses of Social Issues and Public Policy, 12(1), 364-376. doi:10.1111/j.1530-2415.2011.01279.x.

Gilens, M. (2001). Political ignorance and collective policy preferences. The American Political Science Review, 95(2), 379-396. doi:10.2307/3118127?ref=no-x-route:8cfc88d2a807b7fabe2f4106aeed8dcb.

Hofstetter, C. R., Barker, D., Smith, J. T., Zari, G. M., \& Ingrassia, T. A. (1999). Information, misinformation, and political talk radio. Political Research Quarterly, 52(2), 353-369. doi:10.2307/449222?ref=no-x-route:6d9816655d0bff55fc7c001c1bb54e85.

Holan, A. D. (2013, 24 September). Top 16 myths about the health care law. Tampa Bay Times Politifact. Retrieved 27 April 2015, from http://www.politifact.com/truth-o-meter/ article/2013/sep/24/top-16-myths-about-health-care-law/

Jerit, J., \& Barabas, J. (2006). Bankrupt rhetoric: How misleading information affects knowledge about Social Security. Public Opinion Quarterly, 70(3), 278.

Krosnick, J. A., Malhotra, N., \& Mittal, U. (2014). Public misunderstanding of political facts: How question wording affected estimates of partisan differences in birtherism. Public Opinion Quarterly, 78(1), 147 -165. doi:10.1093/poq/nft080. 
Kuklinski, J. H., \& Quirk, P. (2001). Conceptual foundations of citizen competence. Political Behavior, 23(3), 285-311.

Kuklinski, J. H., Quirk, P. J., Jerit, J., Schwieder, D., \& Rich, R. F. (2000). Misinformation and the currency of democratic citizenship. The Journal of Politics, 62(3), 790-816. doi:10.1111/0022-3816.00033.

Kull, S., Ramsay, C., \& Lewis, E. (2003). Misperceptions, the media, and the Iraq war. Political Science Quarterly, 118(4), 569-598.

Luskin, R. C., \& Bullock, J. G. (2011). “Don't know” means “don't know”: DK responses and the public's level of political knowledge. The Journal of Politics, 73(2), 547-557. doi:10.1017/S0022381611000132.

Luskin, R. C., Fishkin, J. S., \& Jowell, R. (2002). Considered opinions: Deliberative polling in Britain. British Journal of Political Science, 32(3), 455-487.

Meirick, P. C. (2013). Motivated misperception? Party, education, partisan news, and belief in "death panels". Journalism \& Mass Communication Quarterly, 90(1), 39-57. doi:10.1177/1077699012468696.

Mondak, J. J. (2001). Developing valid knowledge scales. American Journal of Political Science, 45(1), 224-238.

Mondak, J. J., \& Davis, B. C. (2001). Asked and answered: Knowledge levels when we will not take "don't know" for an answer. Political Behavior, 23(3), 199-224.

Nyhan, B. (2010). Why the "death panel" myth wouldn't die: Misinformation in the health care reform debate. The Forum, 8(1). doi:10.2202/1540-8884.1354.

ObamaCare Facts. (n.d.). ObamaCare: Pros and cons of ObamaCare. Retrieved 27 April 2015, from http://obamacarefacts.com/obamacare-pros-and-cons/

Ortoleva, P., \& Snowberg, E. (2013). Overconfidence in political behavior. Working Paper No. 19250, National Bureau of Economic Research, Cambridge, MA. Retrieved from nber.org

Pasek, J., Stark, T. H., Krosnick, J. A., \& Tompson, T. (2014). What motivates a conspiracy theory? Birther beliefs, partisanship, liberal-conservative ideology, and anti-Black attitudes. Electoral Studies. doi:10.1016/j.electstud.2014.09.009.

Prasad, M., Perrin, A. J., Bezila, K., Hoffman, S. G., Kindleberger, K., Manturuk, K., \& Powers, A. S. (2009). “There must be a reason": Osama, Saddam, and inferred justification. Sociological Inquiry, 79(2), 142-162. doi:10.1111/j.1475-682X.2009.00280.x.

Prior, M., Sood, G., \& Khanna, K. (2013). You cannot be serious: Do partisans believe what they say? Paper presented at the Annual Meeting of the Midwest Political Science Association, Chicago, IL.

TruthorFiction.com. (2015, 17 March). Various emails about the proposed Health Care Bill-Truth! Fiction! \& Disputed! Retrieved 27 April 2015, from http://www.truthorfiction.com/health-plan/

U.S. Department of Health and Human Services. (2013, 7 June). Key features of the Affordable Care Act. Retrieved 27 April 2015, from http://www.hhs.gov/healthcare/facts/timeline/ index.html

\section{Supporting Information}

Additional supporting information may be found in the online version of this article: Appendix S1. Instructions for answering the information items. 